\title{
Optimizing Vascular Risk Reduction in the Stroke Patient with Atherothrombotic Disease
}

\author{
Bruce Ovbiagele \\ Stroke Center and Department of Neurology, Medical Center, University of California at Los Angeles, \\ Los Angeles, Calif., USA
}

\section{Key Words}

Atherosclerosis · Stroke • Ischemic stroke $\cdot$ Risk factors •

Antiplatelet $\cdot$ Statins $\cdot$ Antihypertensives $\cdot$ Endarterectomy

\begin{abstract}
Introduction: With mounting evidence underscoring the multifactorial pathogenesis of atherothrombotic cerebrovascular disease, it is becoming increasingly obvious that an early and aggressive multimodal treatment of the underlying atherosclerotic disease process is the most effective approach towards preventing recurrent vascular events in the majority of ischemic stroke patients. Knowledge of the evidence behind this strategy and the effective means for implementing it could be useful to the healthcare practitioner caring for stroke and transient ischemic attack (TIA) patients. Review Summary: This review presents the evidence behind the broadening therapeutic options for recurrent vascular event prevention in ischemic stroke patients whose underlying stroke pathophysiologic mechanism is presumed to be due to atherosclerosis. The paper identifies modifiable vascular risk factors associated with recurrent stroke, as well as the clinical trial data on which the latest clinical practice guidelines on recurrent stroke prevention have been based. Therapies discussed include antithrom-
\end{abstract}

botics, statins, antihypertensives, revascularization procedures and lifestyle modification (smoking cessation, exercise and diet education). Finally, successful hospital-based quality improvement programs for initiating and maintaining these evidence-based recurrent stroke prevention treatments are also described. Conclusions: A timely, systematic, evidence-based multimodal preventive approach to atherothrombotic disease in ischemic stroke and TIA patients that transcends the continuum of care will enhance treatment rates and improve clinical outcomes.

Copyright $\odot 2009$ S. Karger AG, Basel

\section{Introduction}

Stroke prevention, especially in patients who have already experienced stroke or transient ischemic attack (TIA), is critical for reducing the burden of disease on patients, their families and society [1]. This is particularly relevant since there are extremely few options for treating a stroke when it actually occurs [1], and the overwhelming majority of acute stroke patients do not receive these treatments [2]. Approximately $30 \%$ of strokes are recurrent in nature [3] and the occurrence of a stroke or TIA is the strongest predictor of a repeat event [4]. The

\section{KARGER}

Fax +41613061234

E-Mail karger@karger.ch

www.karger.com
(C) 2009 S. Karger AG, Basel

$1011-7571 / 10 / 0191-0001 \$ 26.00 / 0$

Accessible online at:

www.karger.com/mpp
Bruce Ovbiagele, MD, MS

Stroke Center and Department of Neurology, University of California at Los Angeles 710 Westwood Plaza

Los Angeles, CA 90095 (USA)

Tel. +1 310794 6379, Fax +1 310267 2063, E-Mail ovibes@mednet.ucla.edu 
majority of these strokes can be attributed to an atherothrombotic mechanism [5].

Since the atherothrombotic disease process is systemic in nature with a variety of manifestations, stroke patients with atherosclerosis frequently have coexistent coronary artery disease and peripheral arterial disease [6], and as such are at risk for vascular events emanating from any of these beds in addition to that of the cervicocephalic arterial tree [7, 8]. Fortunately, several existing and emerging therapies that specifically target the underlying atherosclerotic disease process have been shown in clinical trials to markedly lower the risk of recurrent vascular events including stroke [4]. Still, a high proportion of patients are not receiving appropriate preventive measures in a timely manner, and many misunderstandings remain about the most effective agents and treatment regimens resulting in an evidence-practice gap [9].

This article presents up-to-date information on the following topics for the practitioner caring for the ischemic stroke or TIA patient to consider: modifiable risk factors for recurrent stroke and TIA, pertinent clinical trials of stroke prevention, evidenced-based guidelines for recurrent stroke prevention, and ways to improve treatment compliance.

\section{Stroke Morbidity and Mortality}

Worldwide, stroke is surpassed only by heart disease as a leading cause of death [10]. Approximately $22 \%$ of men and $25 \%$ of women with a first stroke die within 1 year, while four fifths of patients do not survive to 10 years [11]. These percentages are even higher among those over age 65. In addition, disability that often accompanies stroke can have a devastating effect on independence and quality of life. For stroke survivors, the medical, social and economic consequences are considerable: $15-30 \%$ of stroke survivors are permanently disabled, and 20\% require institutional care 3 months after the debilitating event [11]. Beyond the occurrence of the index cerebrovascular event, approximately one third of stroke survivors will have a recurrent stroke, and one fifth a myocardial infarction (MI), within 5 years [12]. The short-term risk of a cerebrovascular event is also not inconsequential. Stroke risk following an index stroke or TIA is about $18.5 \%$ at 90 days after the event. Of additional concern is that the impact of a recurrent stroke is more devastating than that of a first-time stroke, with the 30-day mortality rate after a recurrent stroke being almost double that after a first-ever stroke (41 vs. $22 \%$ ) [13].

Med Princ Pract 2010;19:1-12
Table 1. Modifiable stroke risk factors

Hypertension

Cardiac disease

Atrial fibrillation

Dyslipidemia

Carotid stenosis

Diabetes

Cigarette smoking

Physical inactivity

Heavy alcohol use ${ }^{1}$

${ }^{1}$ Binge drinking or $\geq 4$ alcoholic beverages per day.

\section{Stroke Risk Factors}

The first step in any approach to stroke prevention is the identification of predisposing risk factors. The focus of this section will be on those stroke risk factors that are associated with atherothrombotic disease. Most of the known biological and lifestyle risk factors associated with cerebrovascular disease were identified decades ago from large longitudinal studies, but some of the stroke risk factors are nonmodifiable and therefore cannot be the target of intervention.

Advanced age is the most potent nonmodifiable risk factor for stroke. For instance, stroke risk in persons $\geq 65$ years is 16-25 times higher when compared to relatively younger persons [4]. Sex, family history, and race also display a positive correlation with stroke incidence. Men are 1.25 times more likely to suffer stroke than women, even though women account for $60 \%$ of stroke fatalities [11]. Blacks also appear to be at greater risk for stroke incidence and mortality than whites [11]. Risk factors that are not directly modifiable still put patients at high risk for recurrent stroke and therefore dictate an overall more aggressive management strategy [4]. However, there are modifiable risk factors (table 1), which are discussed in a broader context in the sections on pharmacotherapy and lifestyle modification. These stroke risk factors are very well known, but optimal control of these factors in stroke and TIA patients remains a challenge [9].

\section{Transient Ischemic Attack}

TIA and stroke are both risk factors for recurrent stroke. In fact, recognition of this by clinicians is essential in the prevention of recurrent stroke. TIAs are presently defined as temporary interruptions in blood flow to the 
Table 2. ABCD-2 score: scale for predicting 2-day stroke risk after a TIA [16]

\begin{tabular}{ll}
\hline Characteristic & Description \\
\hline Age & $\geq 60$ years \\
Blood pressure & $\begin{array}{l}\text { systolic blood pressure } \geq 140 \text { or } \\
\text { diastolic blood pressure } \geq 90 \mathrm{~mm} \mathrm{Hg} \\
\text { unilateral weakness } \\
\text { Speech impairment without weakness }\end{array}$ \\
Duration of symptoms & $\geq 60$ min \\
& $\begin{array}{l}10-59 \text { min } \\
\text { self-reported history }\end{array}$ \\
\hline
\end{tabular}

brain that cause sudden and discrete neurologic deficits lasting less than $24 \mathrm{~h}$ [14]. However, vascular neurology experts believe that TIAs should be redefined on the basis of evidence that brain tissue can be damaged, even if obvious symptoms resolve in less than $24 \mathrm{~h}$. Therefore, the duration of symptoms is now considered to be a poor indicator of event type, and any patient who presents with transient neurologic deficits suggestive of a TIA should undergo full investigation into the sources of underlying cerebrovascular risk; appropriate prevention strategies should then be initiated early before disabling stroke occurs [14].

Indeed, TIA carries with it a substantial risk of future stroke. A population-based study found that stroke risk after a TIA was $9.5 \%$ at 90 days and $14.5 \%$ at 1 year. In a cohort study of 1,707 patients identified by emergency department physicians as having had a TIA, a 10.5\% risk of subsequent stroke within 90 days was identified - this is 50 times the expected risk for an age-matched cohort [15]. It is important to note that this study also found that for more than half of those who had a subsequent stroke within the 90-day period, this second stroke occurred within $48 \mathrm{~h}$ of the TIA [15]. Risk factors for TIA are similar to risk factors for stroke; hypertension, diabetes, and advanced age are all associated with an increased risk of stroke 1 year after an initial TIA [14].

Symptoms of TIA vary depending upon the affected vascular territory. Carotid artery ischemia often leads to visual disturbance such as transient graying, fogging, or blurring of vision, or an appearance of a 'shade' over the field of vision. Hemispheral ischemia may cause weakness or numbness of the contralateral face or limbs and is associated with language difficulties or cognitive/behavioral changes. Vertebrobasilar TIAs may be associated with ataxia, dizziness, vertigo, dysarthria, abnormal eye movements, disturbed vision, and unilateral or bilateral motor sensory symptoms. A new scoring system for assessing short-term stroke risk was developed to help clinicians determine which TIA patients might require emergency care and/or hospitalization and was published in early 2007 [16]. The ABCD system takes into account several clinical characteristics (table 2) and unlike other stroke risk scales was specifically designed to predict stroke risk within this critical 2-day window. Readers should consult the full reference for complete information on using this system [16].

\section{Pharmacotherapies}

Three main classes of pharmacotherapy have been shown to have substantial impact on cardiovascular and stroke risk. Antithrombotic agents, antihypertensive agents and statins treat the basic underlying pathophysiology of atherosclerosis through independent and likely synergistic mechanisms.

\section{Antiplatelet Therapy}

A meta-analysis by the Antithrombotic Trialists' Collaboration assessed the effect of antiplatelet therapy in patients with various manifestations of atherosclerosis [17]. In total, this analysis included 135,000 patients in comparisons of antiplatelet agents versus control and 77,000 patients in comparisons of different antiplatelet regimens. This meta-analysis found that overall, antiplatelet therapy reduces the combined odds of stroke, MI or vascular death by $22 \%$, and that antiplatelet agents reduce the odds of a nonfatal stroke by $25 \%$ over a wide range of patients with or without a history of stroke [17].

\section{Single Antiplatelet Therapy}

Aspirin prevents platelet activation by inhibiting the enzyme cyclooxygenase, thereby blocking thromboxane generation. Aspirin reduces the relative risk of stroke recurrence by $13-18 \%$ [18]. Data from numerous trials establish that aspirin reduces the risk of stroke, MI and vascular death in a wide variety of patients who are at high risk for these atherothrombotic outcomes. There were no important differences in preventing stroke and other vascular events for various doses of aspirin between 30 and $1,300 \mathrm{mg}$ per day [18-21]. However, low-dose aspirin ap- 
pears to be better tolerated and several international consensus guidelines emphasize using doses of aspirin between 50 and $325 \mathrm{mg}$ per day.

\section{Adenosine Diphosphate Receptor Antagonists}

Adenosine diphosphate (ADP) receptor antagonists inhibit ADP-induced fibrinogen binding to platelets, a necessary step in the platelet aggregation process. Studies have demonstrated that the ADP receptor antagonist clopidogrel effectively prevents stroke in patients with evidence of vascular disease. The CAPRIE study was comprised of 19,185 patients with recent ischemic stroke, MI or peripheral arterial disease [22]. The CAPRIE results indicated a statistically significant advantage of clopidogrel over aspirin, based on an $8.7 \%$ relative risk reduction (RRR) in the composite endpoint of ischemic stroke, MI or vascular death. This advantage over aspirin was enhanced in high-risk patients and patients with a history of stroke or MI [22]. The safety profile of clopidogrel is superior to that of ticlopidine (another ADP receptor antagonist), which is rarely used today due to cases of hematologic dyscrasia such as agranulocytosis and aplastic anemia.

\section{Double Antiplatelet Therapy}

\section{Extended-Release Dipyridamole plus Aspirin}

Dipyridamole increases the plasma concentration of the endogenous platelet inhibitor adenosine by inhibition of adenosine uptake into red blood cells and attenuation of adenosine catabolism. Platelet aggregation in response to various stimuli such as platelet-activating factor, collagen and ADP is inhibited. However, dipyridamole is a pleiotropic agent whose stroke-deterring effects are probably mediated not only by direct actions on the platelet, but also several other mechanisms.

The combination of aspirin and extended-release dipyridamole (ERDP) has been tested and found to be more effective than aspirin alone in stroke prevention. The ESPS-2 study enrolled patients who had experienced either an ischemic stroke or TIA into 4 treatment groups as follows: $25 \mathrm{mg}$ of aspirin, $200 \mathrm{mg}$ of ERDP, $25 \mathrm{mg}$ of aspirin plus $200 \mathrm{mg}$ of ERDP, and placebo [18]. A total of 6,602 patients were followed for 2 years showing that both ERDP and aspirin had an independent and statistically significant effect in reducing the risk of stroke recurrence (16 and 18\%) when compared with placebo. The combi- nation of ERDP plus aspirin reduced the risk of nonfatal and fatal stroke by $23 \%$ compared to aspirin alone and by $37 \%$ compared to placebo [18].

The European/Australasian Stroke Prevention in Reversible Ischaemia Trial (ESPRIT) was an open-label study enrolling patients who experienced nondisabling atherosclerotic stroke or TIA within 6 months of randomization [23]. One study arm compared dipyridamole (400 mg) and aspirin combinations versus aspirin alone and involved a range of aspirin doses between 30 and 325 mg per day (mean aspirin dose $<75 \mathrm{mg} /$ day). Another arm of the study compared oral anticoagulation versus aspirin. The primary outcome measure in ESPRIT was a composite including death from all vascular causes, nonfatal stroke, nonfatal MI, or major bleeding complication. Secondary endpoints included TIA and other vascular events. Over a mean follow-up of 3.5 years, among the 2,739 patients in the treatment arm comparing aspirin versus aspirin plus dipyridamole, 389 patients suffered at least one primary outcome event, including 173 patients randomized to aspirin plus dipyridamole (13\%) and 216 patients randomized to aspirin alone (16\%). The hazard ratio (HR) for the primary outcome event was 0.80 (95\% CI 0.66-0.98), while for ischemic events the HR was 0.81 (95\% CI 0.65-1.01) [23]. Although there were limitations (e.g. open-label design), the results of ESPRIT were consistent with the ESPS-2 results in that they establish a benefit for aspirin plus dipyridamole versus aspirin alone in the secondary prevention of vascular events after ischemic stroke [23].

\section{Clopidogrel plus Aspirin}

In the Management of Atherothrombosis with Clopidogrel in High-Risk Patients with Recent Transient Ischemic Attack or Ischemic Stroke (MATCH) study, patients with a recent ischemic cerebrovascular event and at high risk of recurrent ischemia received low-dose aspirin (75 $\mathrm{mg}$ ) or placebo against a background of ongoing clopidogrel $(75 \mathrm{mg})$ therapy [24]. At follow-up after 1 year, clopidogrel plus aspirin provided no additional benefit over clopidogrel alone for the combined risk of ischemic stroke, MI, vascular death, or rehospitalization for ischemic events. Furthermore, the addition of aspirin to clopidogrel resulted in significantly more life-threatening (2.6 vs. $1.3 \%)$ and major bleeding complications (1.9 vs. $0.6 \%)$ than did clopidogrel alone [24]. Clopidogrel is a useful alternative to aspirin, particularly in aspirin-intolerant patients, but it should be used in combination with aspirin only in patients who present with acute coronary syndromes [24]. 
Clopidogrel for High Atherothrombotic Risk and Ischemic Stabilization, Management, and Avoidance (CHARISMA) was a prospective, multicenter, randomized, double-blind, placebo-controlled study comparing the efficacy and safety of clopidogrel plus aspirin with that of aspirin alone in patients at high risk for a cardiovascular event [25]. The primary efficacy endpoint was the first occurrence of MI, stroke (of any cause), or death from cardiovascular causes (including hemorrhage). The rate of the primary efficacy endpoint was $6.8 \%$ with clopidogrel plus aspirin and $7.3 \%$ with placebo plus aspirin (relative risk 0.93; 95\% CI 0.83-1.05; $\mathrm{p}=0.22$ ). Clopidogrel was not superior to placebo for the primary and secondary endpoints. The CHARISMA trial showed that the combination of clopidogrel plus aspirin was not significantly more effective than aspirin alone in reducing the rate of MI, stroke, or death from cardiovascular causes among patients with stable cardiovascular disease or multiple cardiovascular risk factors. The trial also showed that the risk of moderate bleeding was increased with clopidogrel. The findings do not support the use of clopidogrel plus aspirin therapy across the broad population tested [25].

\section{ERDP plus Aspirin vs. Clopidogrel}

The Prevention Regimen for Effectively Avoiding Second Strokes (PRoFESS) trial, the largest secondary stroke prevention trial ever conducted, was a double-blind, 2by-2 factorial trial with 700 study sites and 20,332 subjects [26]. PRoFESS randomly assigned patients with a history of ischemic stroke to receive $25 \mathrm{mg}$ of aspirin plus $200 \mathrm{mg}$ of ERDP twice daily or to receive $75 \mathrm{mg}$ of clopidogrel daily and followed them for a mean of 2.5 years. The primary outcome was first recurrence of stroke. Recurrent stroke occurred in 916 patients $(9.0 \%)$ receiving aspirin plus ERDP and in 898 patients (8.8\%) receiving clopidogrel (HR 1.01; 95\% CI 0.92-1.11). The secondary outcome occurred in 1,333 patients (13.1\%) in each group (HR 0.99; 95\% CI 0.92-1.07). There were more major hemorrhagic events among aspirin plus ERDP recipients (4.1\%) than among clopidogrel recipients (3.6\%) (HR 1.15; 95\% CI 1.00-1.32), including intracranial hemorrhage (HR 1.42; 95\% CI 1.11-1.83). The net risk of recurrent stroke or major hemorrhagic event was similar in the two groups: aspirin plus ERDP recipients (11.7\%) versus clopidogrel recipients (11.4\%) (HR 1.03; 95\% CI 0.95-1.11).

Consensus guidelines recommend that agents include aspirin, aspirin plus ERDP and clopidogrel monotherapy as acceptable options for initial therapy in recurrent stroke prevention [4]. It is expected that the guide- lines will be updated shortly to reflect the results of the PRoFESS trial.

\section{Warfarin}

Anticoagulant therapy is of benefit in patients with a history of atrial fibrillation that puts them at risk for cardioembolic stroke [4]. However, warfarin is not more effective than aspirin for the prevention of noncardioembolic stroke. In a 2001 head-to-head comparison of warfarin and aspirin for the secondary prevention of noncardioembolic stroke (the WARSS trial), there was no difference in recurrent stroke rates over a 2-year followup period and no difference in adverse event rates, at the time suggesting that both treatments were reasonable therapeutic options [27]. Furthermore, in a more recent randomized controlled trial of 569 patients with symptomatic intracranial stenosis (the WASID trial), warfarin was associated with significantly higher adverse event rates and demonstrated no benefit over aspirin for stroke prevention [28]. In fact, this study was discontinued early because of the increased rates of death, major hemorrhage or MI among patients receiving warfarin [28].

\section{Antihypertensive Agents}

The use of antihypertensive treatment has been shown to reduce this risk of secondary stroke in hypertensive individuals substantially [4]. Those with blood pressure considered normal ( $\leq 140 / 90 \mathrm{~mm} \mathrm{Hg}$ ) with stroke risk factors such as vascular disease, diabetes plus 1 other cardiovascular risk factor, or a history of stroke or TIA may also benefit from antihypertensive medication treatment. The overall effect of treating hypertension is a $30 \%$ reduction in the risk of recurrent stroke.

\section{Modulators of the Renin-Angiotensin System}

Angiotensin-converting enzyme (ACE) inhibitors and angiotensin receptor blockers are both therapeutic agents that attenuate the effects of the renin-angiotensin system. This system has been implicated in the basic underlying mechanism of hypertension and also in mechanisms involved in atherogenesis and endothelial dysfunction [29]. The renin-angiotensin system is involved in vascular remodeling, oxidative stress, and inflammation. It promotes atherosclerosis by interacting with the endothelium and promoting the inflammatory processes. The endothelium is responsible for maintaining vascular homeostasis and is strongly influenced by the interplay between nitric oxide and angiotensin II. Improving en- 
dothelial function may be an important intervention for stroke prevention as both animal and human studies have shown that decreasing angiotensin II production through ACE inhibition can improve vascular compliance and endothelial function [29].

The Perindopril Protection against Recurrent Stroke Study (PROGRESS) enrolled 6,105 patients randomized to active therapy with the ACE inhibitor perindopril with or without the thiazide diuretic versus placebo, in a doubleblinded fashion for a mean follow-up of 3.9 years [30]. The active treatment arm had a $28 \%$ RRR in stroke: the most dramatic finding was that combination therapy with both ACE inhibitor and thiazide diuretic was associated with a lower risk of total stroke (RRR 43\%), fatal or disabling stroke (RRR 46\%), ischemic stroke (RRR 36\%), and cerebral hemorrhage (RRR 76\%) as compared to placebo [30].

In the second part of the PRoFESS trial, the investigators randomly assigned patients with a history of a recent ischemic stroke to receive telmisartan ( $80 \mathrm{mg}$ daily) versus placebo [31]. The primary outcome as previously noted was recurrent stroke. During the mean follow-up of 2.5 years, mean blood pressure was 3.8/2.0 $\mathrm{mm} \mathrm{Hg}$ lower in the telmisartan group compared to the placebo group. A total of 880 patients $(8.7 \%)$ in the telmisartan group versus 934 patients $(9.2 \%)$ in the placebo group experienced a stroke (HR in the telmisartan group $0.95 ; 95 \% \mathrm{CI}$ $0.86-1.04 ; \mathrm{p}=0.23$ ). Major cardiovascular events occurred in $13.5 \%$ of the patients in the telmisartan group versus $14.4 \%$ in the placebo group (HR 0.94; 95\% CI 0.87$1.01 ; \mathrm{p}=0.11$ ). Post hoc exploratory analyses indicated that the number of patients who had a recurrent stroke during the first 6 months was 3.4\% in the telmisartan group versus $3.2 \%$ in the placebo group (HR 1.07; 95\% CI $0.92-1.25)$. After 6 months, $5.3 \%$ of the subjects in the telmisartan group had a recurrent stroke versus $6.0 \%$ in the placebo group (HR 0.88; 95\% CI 0.78-0.99). The difference in effects that were observed during the two periods was significant ( $p=0.04$ for interaction). The takehome message from this part of the PRoFESS trial was that over the study period therapy with telmisartan initiated after the occurrence of an ischemic stroke and continued for 2.5 years did not significantly lower the rate of recurrent stroke, but the effect of telmisartan on recurrent stroke may be time-dependent [31].

\section{Thiazide-Type Diuretics}

Thiazide diuretics act by inhibiting tubular resorption of sodium and chloride ions in the ascending loop of Henle and early distal tubule [29]. This results in excretion of water, sodium and chloride. The net effect is a de- crease in peripheral vascular resistance. Thiazides have been associated with decreased rates of stroke in many different types of studies and populations. In a case-control study of treated hypertensive patients, antihypertensive drug regimens that did not include a thiazide diuretic were associated with an increased risk of ischemic stroke compared with regimens that did include a thiazide [29]. In the randomized, placebo-controlled trial PATS (The Post-stroke Antihypertenensive Treatment Study), the thiazide-like diuretic indapamide was evaluated in secondary stroke prevention in 5,665 people [32]. Treatment with thiazides was associated with a $5 / 2 \mathrm{~mm}$ $\mathrm{Hg}$ reduction in blood pressure and a 29\% RRR of stroke at 3 years compared to placebo [32]. The PROGRESS trial as noted previously found that combined therapy with indapamide and perindopril but not perindopril alone reduced the risk of recurrent stroke [30].

Based on the PROGRESS trial, the JNC-7 recommends the combination of a thiazide-type diuretic and an ACE inhibitor for patients with cerebrovascular disease [33]. In patients with stage 2 hypertension (systolic blood pressure $\geq 160 \mathrm{~mm} \mathrm{Hg}$ or diastolic blood pressure $\geq 100 \mathrm{~mm}$ $\mathrm{Hg}$ ), the JNC-7 guidelines indicate treatment with a combined 2-drug antihypertensive regimen should be initiated [33].

\section{Statins (HMG-CoA Reductase Inhibitors)}

Several major lipid-lowering trials have shown that statin therapy reduces overall vascular risk, and the role of statins in preventing primary stroke among persons with or at risk of cardiovascular disease is well established [29]. However, until recently the benefits of statins in the secondary prevention of vascular events after an ischemic stroke or TIA were largely unproven [29]. The mechanisms by which statins confer vascular protection are multifactorial, but the best-described and probably primary actions are upregulation of low-density lipoprotein (LDL) receptor activity and reduction of LDL entry into the circulation [34]. Statins are believed to harbor other beneficial actions that may contribute to preventing stroke occurrence (table 3). The Stroke Prevention by Aggressive Reduction in Cholesterol Levels (SPARCL) study was the first clinical trial of statins specifically designed to study ischemic stroke and TIA patients (1-6 months after the index event) with normal or average cholesterol levels at the time of study initiation and no evidence of coronary heart disease [35]. SPARCL enrolled 4,731 subjects randomly assigned to receive high-dose atorvastatin $(80 \mathrm{mg} /$ day) or placebo over an average of 4.4 years of follow-up [35]. 
Statin treatment was associated with a $38 \%$ reduction in $\mathrm{LDL}$ compared to a $7 \%$ reduction in the placebo group that translated into a $16 \%$ relative reduction in the primary endpoint of any recurrent stroke [35]. This overall net stroke-reducing benefit comprised reductions in fatal stroke and ischemic stroke but an increase in hemorrhagic stroke. The number needed to treat for the prevention of 1 stroke over 5 years was 46, and to prevent a major cardiovascular event, 29 [35].

Subjects randomized to active therapy in SPARCL had a higher rate of intracerebral hemorrhage (ICH) (HR 1.68). Factors associated with an increased risk of $\mathrm{ICH}$ in SPARCL were: ICH as the entry event, increasing age, and stage 2 hypertension; however, being female appeared to be protective [34]. Uncontrolled hypertension at the last study visit prior to $\mathrm{ICH}$ occurrence was also associated with an increased risk. There was no relationship between LDL level and risk of ICH [34].

As the net vascular benefit from statin treatment far outweighs the risk of $\mathrm{ICH}$, at this time it would appear that the overwhelming majority of ischemic stroke patients should be treated with a statin without undue concern for ICH, especially in the setting of good blood pressure control $(<140 / 90 \mathrm{~mm} \mathrm{Hg})$ [34].

The American Stroke Association recommends that a statin be initiated during hospitalization for first ischemic stroke of atherosclerotic origin [4]. This guideline is to be applied to ischemic strokes caused by small vessel disease or large vessel atherosclerosis. Treatment dose should depend on an individual's vascular risk, but for patients with atherosclerotic stroke an LDL cholesterol goal of $<100 \mathrm{mg} / \mathrm{dl}(2.6 \mathrm{mmol} / \mathrm{l})$ should be targeted. Selected patients at very high risk should have an LDL cholesterol goal of $<70 \mathrm{mg} / \mathrm{dl}(1.8 \mathrm{mmol} / \mathrm{l})$ [4].

\section{Lifestyle Modification}

\section{Smoking Cessation}

Smoking causes increased arterial wall stiffness resulting in reduced distensibility and compliance [29]. In addition, it is associated with increased fibrinogen levels, increased platelet aggregation, decreased high-density lipoprotein (HDL) cholesterol levels and increased hematocrit. Benefits from quitting are seen in former smokers even after many years of heavy smoking [29].

The stroke risk associated with former smoking has been shown to substantially decrease with increasing time since cessation and returns to the risk level of nonsmokers at 5 years from cessation. The risk is dependent
Table 3. Pleiotropic actions of statins

Improving endothelial function

Decreasing serum markers of chronic inflammation

Upregulation of genes

Plaque stabilization

Antithrombotic effects

Antioxidant effects

Antiinflammatory effects

Neuroprotective effects

Improving HDL function

upon the number of cigarettes smoked and is consistent for all subtypes of stroke. Evidence is also accumulating to implicate pipe and cigar smoking as a risk factor for stroke, and passive exposure to environmental smoke as a risk factor for atherogenesis. Prospective studies assessing modification of smoking habits showed that $21.7 \%$ gave up smoking at 6 months after having inpatient counseling [29].

All stroke patients should be screened for this risk factor. Based on these and other cohort and epidemiological studies, a consensus committee of healthcare professionals from the Stroke Council of the American Heart Association have recommended immediate smoking cessation advice be given to all current smokers [4]. Those who are current or recent smokers should undergo inpatientinitiated smoking cessation intervention. As rates of quitting tobacco in the long term are poor, any smoking cessation program needs to include long-term follow-up. Additionally, factors that promote smoking such as stress and depression should be addressed.

\section{Diet and Obesity}

High daily dietary intake of fat is associated with obesity and may act as an independent risk factor or may affect other stroke risk factors such as hypertension, diabetes, hyperlipidemia, and cardiac disease [29]. There is evidence that certain types of diets can be particularly effective in treatment of cardiovascular and stroke risk independent of weight loss. There may be a protective relationship between stroke and the consumption of fruits and vegetables, especially cruciferous and green leafy vegetables and citrus fruit and juice [29]. Analysis of data from the Nurses Health Study and Health Professionals Follow-up Study found that an increment of 1 serving of fruit and vegetables was associated with a $6 \%$ lower risk of stroke. 
Abdominal obesity is an independent, potent risk factor for ischemic stroke in all race-ethnic groups [36]. It is a stronger risk factor than BMI and has a greater effect among younger persons [36]. Compared with men with low normal weight, men with a BMI $>30.0$ had an adjusted HR of 1.93 for total stroke. Proper diet in combination with increased activity is the most effective way to lose weight. One study found that $85.4 \%$ of those who had received dietary advice reported a dietary change compared with $56.0 \%$ of those who had not received such advice [37].

The American Heart Association Diet Guidelines are an important resource for prescribing a diet that will lead to weight loss and improved cardiovascular outcomes [4]. Patients with prior stroke should be advised to eat fewer high fat/high cholesterol foods. Increasing evidence supports the benefits of maintaining normal body weight for reducing risk of cardiovascular disease. Initiation and maintenance of the American Heart Association diet provide a means for achieving these goals while ensuring an overall balanced and nutritious dietary pattern. Intervention through nutritional counseling and a doctor-prescribed exercise regimen may help patients comply with the guideline recommendations and more successfully lose weight [29].

The protective effect of physical activity may be mediated in part through its role in controlling known stroke risk factors like hypertension, cardiovascular disease, diabetes, and body weight [29]. Other possible mechanisms including reductions in fibrinogen and platelet activity as well as elevations in plasma tissue plasminogen activator activity and HDL concentrations play a role [29].

Lifestyle and behavior modifications that include exercise are effective in the prevention of cardiovascular disease and stroke. The benefits are manifested largely through the role that exercise plays in the control of certain modifiable risk factors, such as control of blood lipid abnormalities, diabetes and obesity [29]. Exercise also adds an independent effect in the lowering of blood pressure in certain hypertensive groups, thus favorably modifying a major risk factor for stroke. An aerobic conditioning program can enhance glucose regulation and promote decreases in body weight and fat stores, blood pressure, C-reactive protein, and levels of total blood cholesterol, serum triglycerides, and LDL cholesterol. Exercise also increases HDL cholesterol and improves coronary artery endothelial function. These findings are consistent with the growing body of evidence that interventions that promote plaque stability, favorable changes in vascular wall function, or both have important implica- tions for the medical management of patients after a stroke or other vascular event [29].

Guidelines recommend that Americans should exercise for at least 30 min of moderately intense physical activity on most, and preferably all, days of the week [29]. For stroke, the benefits are apparent even for light to moderate activities such as walking and increasing the level and duration of one's recreational activity. A goal for stroke survivors should be to improve aerobic fitness, notwithstanding residual functional limitations. All patients with ischemic stroke should have exercise counseling [29].

\section{Patient Education}

Knowing that stroke is a highly preventable condition and being aware of the importance of risk factor and lifestyle modification can be especially effective when a patient is admitted to the hospital and focused on her or his health [29]. The general population and particularly those at risk for stroke unfortunately have a very poor knowledge of stroke and stroke risk factors [29]. There is ample evidence that stroke education can have an impact among individuals and communities for prevention and more rapid presentation. A high-risk screening and education program in Taiwan demonstrated the impact of stroke education which was linked to an impressive decrease in the stroke mortality rate when compared to the reference community [29].

\section{Revascularization Procedures}

\section{Carotid Endarterectomy}

Internal carotid artery (ICA) stenosis is an important cause of TIAs and stroke, accounting for $10-20 \%$ of cases. The most common cause of ICA stenosis is atherosclerosis. Data from three large randomized trials of high-grade symptomatic ICA stenosis (The North American Symptomatic Carotid Endarterectomy Trial, European Carotid Surgery Trial, Veterans Affairs Cooperative) have demonstrated a clear advantage of carotid endarterectomy (CEA) [4]. CEA increased the 5-year risk of ipsilateral ischemic stroke in patients with $<30 \%$ stenosis, had no effect in those with $30-49 \%$ stenosis, had marginal benefit in those with $50-69 \%$ stenosis, but was of greatest benefit in patients with $\geq 70 \%$ stenosis but without near occlusion (adjusted risk reduction [ARR] 16\%; $\mathrm{p}<0.001$ ) [4]. CEA done by a surgeon with a perioperative morbidity and mortality of $<6 \%$ for this procedure is recommended [4]. For those with ipsilateral moderate (50-69\%) 
cervical carotid stenosis, CEA should be considered, and a decision to operate should be based on the patient's age, gender, comorbidities, and severity of initial symptoms. Overall, the benefit from CEA is best if it is performed within 2 weeks after the patient's last ischemic event, the advantage it confers falling rapidly with increasing delay [4]. If carotid stenosis is $<50 \%, \mathrm{CEA}$ is not recommended [4].

The Asymptomatic Carotid Atherosclerosis Study (ACAS) evaluated the efficacy of CEA in patients with a $>60 \%$ asymptomatic ICA stenosis. Patients were aged $40-79$ years and had a $>5$-year life expectancy [38]. The event rate in surgically treated patients for the primary endpoint (ipsilateral stroke, perioperative stroke, or death) was $5.1 \%$ over 5 years, including a $1.2 \%$ angiography risk and $1.1 \%$ surgical risk. The rate of primary endpoint in medically treated patients was $11 \%$, for a $55 \%$ RRR and 6\% ARR ( $\mathrm{p}=0.004)$ [38]. The important factors to consider are the low rate of adverse outcomes in the trial, and patients with $>80 \%$ stenosis benefited more from surgery. CEA for asymptomatic ICA stenosis $>60 \%$ is an acceptable option for patients with a surgical risk $<3 \%$ and a life expectancy of at least 5 years. Patients with $<60 \%$ asymptomatic stenosis do not benefit from CEA [38].

\section{Carotid Angioplasty with Stenting}

Carotid artery stenosis may be treated endovascularly by percutaneous transluminal balloon angioplasty with or without stent insertion or by primary stenting. Endovascular treatment may be a useful alternative to CEA, particularly for lesions not suitable for surgery [29].

Most of the initial data on carotid angioplasty with stenting (CAS) were based on case series, surveys, and enrollment of patients in voluntary registries. The Carotid and Vertebral Artery Transluminal Angioplasty Study (CAVATAS) was the first major trial to be completed and included patients with carotid stenosis in whom there was uncertainty about which procedure was preferable. CEA was performed in 253 patients, carotid artery angioplasty with or without stenting in 251 [39]. Suitable stents became available during the course of the study but were used in only $26 \%(n=55)$ of the procedures. Periprocedural stroke and death rates were higher than in the previous trials of CEA, but were similar for endovascular treatment and surgery (10.0 vs. $9.9 \%)$. The endovascular procedure had less cranial neuropathy $(0$ vs. $8.7 \%$ ), less frequent neck or groin hematoma (1.2 vs. $6.7 \%)$, but more frequently restenosis at 1 year (14 vs. $4 \%$ ) [39].

Multimodal Stroke Prevention
Distal protection devices to capture emboli during angioplasty and stenting have been developed and may decrease the risk of stroke during interventional procedures. The Stenting and Angioplasty with Protection in Patients at High Risk for Endarterectomy (SAPPHIRE) study compared CEA and CAS with the use of one such device in patients with moderate to severe ICA with an increased surgical risk [40]. Major cardiovascular events occurred in $12.2 \%$ of patients in the CAS group and $20.1 \%$ of the CEA group (ARR 7.9\%, $\mathrm{p}=0.004$ for noninferiority).

In the SPACE trial, a multinational, prospective, randomized study to test the hypothesis that CAS is not inferior to CEA for treating patients with severe symptomatic carotid artery stenosis, 1,200 subjects with carotid stenosis $>70 \%$ on duplex ultrasound were randomly assigned within 180 days of a TIA or ischemic stroke to undergo either CAS or CEA. The primary endpoint was ipsilateral ischemic stroke or death at 30 days following the procedure. Final results showed that although the absolute difference in these events between the groups was $0.51 \%$, the $90 \%$ CI crossed zero, ranging from -1.89 to $2.91 \%$, and as such the noninferiority of CAS compared with CEA for the 30-day complication rate was not proven [41]. The SPACE investigators also reported additional results and found that in both the intention-to-treat and per-protocol analyses the occurrence of ipsilateral ischemic strokes or any periprocedural stroke or death up to 2 years after the procedure did not differ between the CAS and the CEA groups [42]. Furthermore, in both the intention-to-treat and per-protocol populations, recurrent stenosis of $\geq 70 \%$ was significantly more frequent in the CAS group compared with the CEA group [42].

The EVA-3S trial was a multicenter, randomized, noninferiority trial to compare stenting with endarterectomy in patients with a symptomatic carotid stenosis of at least $60 \%$ [43]. The primary endpoint was the incidence of any stroke or death within 30 days after the procedure. The EVA-3S trial had to be terminated early after the inclusion of 527 patients due to concerns about safety and futility. The 30-day incidence of any stroke or death was $3.9 \%$ following endarterectomy versus $9.6 \%$ after stenting. The relative risk (i.e. stenting vs. endarterectomy) was 2.5 (95\% CI 1.2-5.1). At 6 months, the incidence of any stroke or death was $6.1 \%$ following endarterectomy vs. $11.7 \%$ after stenting, a difference which was statistically significant $(\mathrm{p}=0.02)$. There were more major local complications after stenting and more systemic complications (mainly pulmonary) after endarterectomy, but these differences did not reach statistical significance.

Med Princ Pract 2010;19:1-12 
Cranial nerve injury was more frequent after endarterectomy compared to stenting [43].

CAS performed by operators with established periprocedural morbidity and mortality rates of $4-6 \%$, may be considered in those with [4]:

- symptomatic severe stenosis $(>70 \%)$ in whom the stenosis is difficult to access surgically;

- medical conditions that greatly increase the surgical risk;

- specific circumstances such as radiation-induced stenosis or restenosis after CEA.

Angioplasty and/or stenting may also be considered when patients with symptomatic extracranial vertebral stenosis are having symptoms despite optimal medical risk factor treatment. Among those with hemodynamically significant stenosis of the major intracranial vasculature (basilar, middle cerebrals, distal carotids and vertebrals) experiencing symptoms despite optimal medical risk factor treatment, angioplasty and/or stenting is considered experimental [4].

\section{Evidence-Practice Gap}

Numerous secondary stroke prevention modalities are now available and there is a copious amount of data that validates the efficacy of quite a few of these therapies [9]. Yet, there exists a large gap in implementing evidence-based secondary prevention strategies. TIA and ischemic stroke patients are often discharged from the hospital without being put on any preventive medication, despite the fact that there is data supporting the use of antiplatelet agents, anticoagulants, and antihypertensives for the prevention of secondary stroke [9]. In addition, there are behavioral interventions that could help patients avoid stroke recurrence, but quite often stroke patients are not being educated about these behaviors during the acute care period. Poor discharge treatment utilization limits the effectiveness of proven therapies, resulting in lost opportunities to reduce the burden of secondary stroke.

All of this notwithstanding, the acute stroke hospitalization setting represents the ideal opportunity to implement evidence-based combination therapies to help prevent early recurrence of stroke and other vascular events [9]. Current clinical management of acute stroke patients has stroke specialists and hospital physicians focusing on the acute management and diagnostic work-up during hospitalization. Initiation of long-term treatments is often deferred to the postdischarge setting when the patient
Table 4. Potential avenues for enhancing further research in closing the stroke prevention evidence-practice treatment gap [9]

1 Evaluation of adherence for periods beyond 1 year

2 Randomized trial data are needed

3 Link stroke quality improvement initiatives with clinical outcomes

4 Other interventions

- Follow-up risk factor control clinics

- Telephone follow-up

- Primary care feedback

- Greater neurologist involvement in postdischarge risk reduction

5 More efficient data capture

6 Funding avenues for implementation research

resumes long-term primary care follow-up. This deferred approach may result in therapy not being initiated or being initiated less efficiently and at a time (weeks or months after the initial presentation) when the stroke event and underlying atherosclerotic disease may no longer be the focus of either the patient or primary care physician. Initiating medications during the acute stroke hospitalization phase sends the message to the patient that these therapies are important for the prevention of recurrent events and are an essential part of his/her treatment. Importantly, hospital initiation of secondary prevention therapies has been shown to be a strong predictor of subsequent use in the community, and is associated with better clinical outcomes [9].

As a means for hospitals to ensure they are implementing the current guidelines, the American Stroke Association developed an interactive, hospital-based quality improvement program called 'Get with the Guidelines-Stroke' (GWTG-Stroke). GWTG-Stroke has tools which help ensure continuous quality improvement of acute stroke treatment and ischemic stroke prevention. It focuses on care team protocols to ensure that patients are treated and discharged appropriately [9]. GWTG-Stroke identifies people (champions) to lead, develop and mobilize teams to implement treatment and discharge guidelines for patients in acute care hospitals [9].

Another program that provides tools for translating evidence-based medicine into clinical care is the UCLA Stroke PROTECT (Preventing Recurrence of Thromboembolic Events through Coordinated Treatment) program [9]. PROTECT is a quality improvement program dedicated to the reduction of recurrent cerebrovascular 
events through improved utilization of proven, evidencebased secondary prevention treatments [9]. The PROTECT program systematically implements 8 medication/ behavioral secondary prevention measures known to improve outcome in patients with cerebrovascular disease at the time of acute TIA or stroke admission. The program's treatment algorithms center on evidence-based combination of medical and behavioral therapies that target the underlying atherosclerotic process [9]. The 4 medication goals are initiation of an antithrombotic, a statin, an ACE inhibitor/angiotensin receptor blocker and a thiazide diuretic. The 4 behavioral interventions are smoking cessation counseling, exercise counseling, diet counseling and education about personal stroke risk factors and the need to call 911 if new stroke symptoms occur. PROTECT has been associated with a substantial increase in treatment utilization at the time of hospital discharge and with high treatment adherence rates at 90 days and 1 year after discharge [9].

Beyond the aforementioned successful programs, there are several other potential avenues to optimize implementation research in stroke prevention and to further bridge the stroke prevention evidence-practice gap (table 4).

\section{Conclusions}

Atherothrombotic disease is a major health burden with significant economic impact. Patients with prior stroke are at significant risk of experiencing a recurrent event or an atherothrombotic event in another vascular bed. A multimodal stroke prevention strategy comprises an early and aggressive therapeutic approach towards slowing the progressive and devastating consequences of atherosclerotic disease. Key guidelines based largely on compelling clinical trial evidence recommend the use of various classes of medications including antithrombotics, statins and antihypertensives, as well as revascularization procedures and lifestyle modification to prevent future atherothrombotic events in patients with a history of stroke or TIA. To enhance adherence to several of these treatments, systematic in-hospital and outpatient evidence-based protocols have been developed and proven to be successful. With the incidence of stroke believed to rise in coming decades due to the graying of the world's population, it will be extremely important for clinicians caring for patients with stroke or TIA presumed to be due to atherosclerosis, to appropriately, effectively and efficiently apply evidence-based vascular risk reduction treatments with the goal of lessening the heavy personal and societal burden of recurrent stroke.

\section{References}

1 Tissue plasminogen activator for acute ischemic stroke. The National Institute of Neurological Disorders and Stroke rt-PA Stroke Study Group. N Engl J Med 1995;333:15811587.

- 2 Nilasena D, Kresowik TF, Wiblin RT, Piskac AF, Kresowik RA, Brenton MA: Assessing patterns of t-PA use in acute stroke. Stroke 2002;33:354.

> Thom T, Haase N, Rosamond W, Howard VJ, Rumsfeld J, Manolio T, Zheng ZJ, Flegal K, O’Donnell C, Kittner S, Lloyd-Jones D, Goff DC Jr, Hong Y, Adams R, Friday G, Furie K, Gorelick P, Kissela B, Marler J, Meigs J, Roger V, Sidney S, Sorlie P, Steinberger J, Wasserthiel-Smoller S, Wilson M, Wolf P: Heart Disease and Stroke Statistics - 2006 Update. A Report from the American Heart Association Statistics Committee and Stroke Statistics Subcommittee. Circulation 2006;113: e85-e151.

4 Sacco RL, Adams R, Albers G, Alberts MJ, Benavente O, Furie K, Goldstein LB, Gorelick P, Halperin J, Harbaugh R, Johnston SC, Katzan I, Kelly-Hayes M, Kenton EJ, Marks M, Schwamm LH, Tomsick T: Guidelines for prevention of stroke in patients with ischemic stroke or transient ischemic attack: a statement for healthcare professionals from the American Heart Association/American Stroke Association Council on Stroke: co-sponsored by the Council on Cardiovascular Radiology and Intervention: the American Academy of Neurology affirms the value of this guideline. Stroke 2006;37:577-617.

5 Warlow C, Dennis MS, Van Gijn J, Hankey GJ, Sandercock PA, Bamford J, Wardlaw J: What caused this ischaemic event?; in: Stroke: a Practical Guide to Management. Oxford, Blackwell Science, 2001, pp 223300.

6 Espinola-Klein C, Rupprecht HJ, Blankenberg S, Bickel C, Peth S, Kopp H, Victor A, Hafner G, Meyer J: [Manifestations of atherosclerosis in various vascular regions. Similarities and differences regarding epidemiology, etiology and prognosis (in German). Med Klin 2002;97:221-228.

7 Rauch U, Osende JI, Fuster V, Badimon JJ, Fayad Z, Chesebro JH: Thrombus formation on atherosclerotic plaques: pathogenesis and clinical consequences. Ann Intern Med 2001; 134:224-238. $\checkmark$ Caplan L: Prevention of strokes and recurrent strokes. J Neurol Neurosurg Psychiatry 1998;64:716.

-9 Ovbiagele B: Pessin Award Lecture 2008: Lessons from the Stroke PROTECT program. J Neurol Sci 2008;275:1-6.

10 Murray CJ, Lopez AD: Mortality by cause for eight regions of the world: Global Burden of Disease Study. Lancet 1997;349:1269-1276.

11 Rosamond W, Flegal K, Furie K, Go A, Greenlund K, Haase N, Hailpern SM, Ho M, Howard V, Kissela B, Kittner S, Lloyd-Jones D, McDermott M, Meigs J, Moy C, Nichol G, O'Donnell C, Roger V, Sorlie P, Steinberger J, Thom T, Wilson M, Hong Y: Heart disease and stroke statistics - 2008 update: a report from the American Heart Association Statistics Committee and Stroke Statistics Subcommittee. Circulation 2008;117:e25-e146.

12 Petty GW, Brown RD Jr, Whisnant JP, Sicks JD, O'Fallon WM, Wiebers DO: Survival and recurrence after first cerebral infarction: a population-based study in Rochester, Minnesota, 1975 through 1989. Neurology 1998; 50:208-216.

13 Hardie K, Hankey GJ, Jamrozik K, Broadhurst RJ, Anderson C: Ten-year risk of first 
recurrent stroke and disability after firstever stroke in the Perth Community Stroke Study. Stroke 2004;35:731-735.

14 Ovbiagele B: Antiplatelet therapy in management of transient ischemic attack: overview and evidence-based rationale. J Emerg Med 2008;34:389-396.

-15 Johnston S, Gress DR, Browner WS, Sidney S: Short-term prognosis after emergency department diagnosis of TIA. JAMA 2000;284: 2901-2906.

16 Johnston SC, Rothwell PM, Nguyen-Huynh MN, Giles MF, Elkins JS, Bernstein AL, Sidney S: Validation and refinement of scores to predict very early stroke risk after transient ischaemic attack. Lancet 2007;369:283-292.

$\checkmark 17$ Antithrombotic Trialists' Collaboration: Collaborative meta-analysis of randomised trials of antiplatelet therapy for prevention of death, myocardial infarction, and stroke in high risk patients. BMJ 2002;324:71-86.

$\checkmark 18$ Diener HC, Cunha L, Forbes C, Sivenius J, Smets P, Lowenthal A: European Stroke Prevention Study. 2. Dipyridamole and acetylsalicylic acid in the secondary prevention of stroke. J Neurol Sci 1996;143:1-13.

19 Swedish Aspirin Low-Dose Trial (SALT) of $75 \mathrm{mg}$ aspirin as secondary prophylaxis after cerebrovascular ischaemic events. The SALT Collaborative Group. Lancet 1991;338:13451349.

20 A comparison of two doses of aspirin $(30 \mathrm{mg}$ vs $283 \mathrm{mg}$ a day) in patients after a transient ischemic attack or minor ischemic stroke. The Dutch TIA Trial Study Group. N Engl J Med 1991;325:1261-1266.

21 Farrell B, Godwin J, Richards S, Warlow C: The United Kingdom transient ischaemic attack (UK-TIA) aspirin trial: final results. J Neurol Neurosurg Psychiatry 1991;54:10441054.

22 A randomised, blinded, trial of clopidogrel versus aspirin in patients at risk of ischaemic events (CAPRIE). CAPRIE Steering Committee. Lancet 1996;348:1329-1339.

-23 Halkes PH, van Gijn J, Kappelle LJ, Koudstaal PJ, Algra A: Aspirin plus dipyridamole versus aspirin alone after cerebral ischaemia of arterial origin (ESPRIT): randomised controlled trial. Lancet 2006;367:16651673.

24 Diener HC, Bogousslavsky J, Brass LM, Cimminiello C, Csiba L, Kaste M, Leys D, Matias-Guiu J, Rupprecht HJ; MATCH Investigators: Aspirin and clopidogrel compared with clopidogrel alone after recent ischaemic stroke or transient ischaemic attack in highrisk patients (MATCH): randomised, double-blind, placebo-controlled trial. Lancet 2004;364:331-337.

- 25 Bhatt DL, Fox KA, Hacke W, Berger PB, Black HR, Boden WE, Cacoub P, Cohen EA, Creager MA, Easton JD, Flather MD, Haffner SM, Hamm CW, Hankey GJ, Johnston SC, Mak KH, Mas JL, Montalescot G, Pearson TA, Steg PG, Steinhubl SR, Weber MA,
Brennan DM, Fabry-Ribaudo L, Booth J, Topol EJ: Clopidogrel and aspirin versus aspirin alone for the prevention of atherothrombotic events. N Engl J Med 2006;354: 1706-1717.

26 Sacco RL, Diener HC, Yusuf S, Cotton D, Ounpuu S, Lawton WA, Palesch Y, Martin RH, Albers GW, Bath P, Bornstein N, Chan BP, Chen ST, Cunha L, Dahlof B, De Keyser J, Donnan GA, Estol C, Gorelick P, Gu V, Hermansson K, Hilbrich L, Kaste M, Lu C, Machnig T, Pais P, Roberts R, Skvortsova V, Teal P, Toni D, Vandermaelen C, Voigt T, Weber M, Yoon BW: Aspirin and extendedrelease dipyridamole versus clopidogrel for recurrent stroke. N Engl J Med 2008;359: 1238-1251.

27 Mohr J, Thompson JL, Lazar RM, Levin B, Sacco RL, Furie KL, Kistler JP, Albers GW, Pettigrew LC, Adams HP, Jackson CM, Pullicino P: A comparison of warfarin and aspirin for the prevention of recurrent ischemic stroke. N Engl J Med 2001;345:1444-1451.

28 Chimowitz MI, Lynn MJ, Howlett-Smith H, Stern BJ, Hertzberg VS, Frankel MR, Levine SR, Chaturvedi S, Kasner SE, Benesch CG, Sila CA, Jovin TG, Romano JG: Comparison of warfarin and aspirin for symptomatic intracranial arterial stenosis. N Engl J Med 2005;352:1305-1316.

-29 Sanossian N, Ovbiagele B: Multimodality stroke prevention. Neurologist 2006;12:1431.

30 PROGRESS Collaborative Group: Randomised trial of a perindopril-based bloodpressure-lowering regimen among 6,105 individuals with previous stroke or transient ischaemic attack. Lancet 2001;358:10331041.

- 31 Yusuf S, Diener HC, Sacco RL, Cotton D, Ounpuu S, Lawton WA, Palesch Y, Martin RH, Albers GW, Bath P, Bornstein N, Chan BP, Chen ST, Cunha L, Dahlof B, De Keyser J, Donnan GA, Estol C, Gorelick P, Gu V, Hermansson K, Hilbrich L, Kaste M, Lu C, Machnig T, Pais P, Roberts R, Skvortsova V, Teal P, Toni D, VanderMaelen C, Voigt T, Weber M, Yoon BW: Telmisartan to prevent recurrent stroke and cardiovascular events. N Engl J Med 2008;359:1225-1237.

- 32 Post-stroke antihypertensive treatment study. A preliminary result. PATS Collaborating Group. Chin Med J (Engl) 1995;108: 710-717.

- 33 Chobanian AV, Bakris GL, Black HR, Cushman WC, Green LA, Izzo JL Jr, Jones DW, Materson BJ, Oparil S, Wright JT Jr, Roccella EJ: The Seventh Report of the Joint National Committee on Prevention, Detection, Evaluation, and Treatment of High Blood Pressure: the JNC 7 report. JAMA 2003;289: 2560-2572.

34 Sanossian N, Ovbiagele B: Drug insight: translating evidence on statin therapy into clinical benefits. Nat Clin Pract Neurol 2008; 4:43-49.
35 Amarenco P, Bogousslavsky J, Callahan A 3rd, Goldstein LB, Hennerici M, Rudolph AE, Sillesen H, Simunovic L, Szarek M, Welch KM, Zivin JA: High-dose atorvastatin after stroke or transient ischemic attack. N Engl J Med 2006;355:549-559.

36 Suk SH, Sacco RL, Boden-Albala B, Cheun JF, Pittman JG, Elkind MS, Paik MC: Abdominal obesity and risk of ischemic stroke: the Northern Manhattan Stroke Study. Stroke 2003;34:1586-1592.

37 Greenlund KJ, Giles WH, Keenan NL, Croft JB, Mensah GA, Huston SL: Physician Advice, Patient Actions, and Health-Related Quality of Life in Secondary Prevention of Stroke Through Diet and Exercise. The Physician's Role in Helping Patients to Increase Physical Activity and Improve Eating Habits. Stroke 2002;33:565-571.

38 Moore WS, Barnett HJ, Beebe HG, Bernstein EF, Brener BJ, Brott T, Caplan LR, Day A, Goldstone J, Hobson RW 2nd, et al: Guidelines for carotid endarterectomy. A multidisciplinary consensus statement from the Ad Hoc Committee, American Heart Association. Circulation 1995;91:566-579.

39 McCabe DJ, Pereira AC, Clifton A, Bland JM, Brown MM: Restenosis after carotid angioplasty, stenting, or endarterectomy in the Carotid and Vertebral Artery Transluminal Angioplasty Study (CAVATAS). Stroke 2005; 36:281-286.

-40 Yadav JS, Wholey MH, Kuntz RE, Fayad P, Katzen BT, Mishkel GJ, Bajwa TK, Whitlow P, Strickman NE, Jaff MR, Popma JJ, Snead DB, Cutlip DE, Firth BG, Ouriel K, the Stenting and Angioplasty with Protection in Patients at High Risk for Endarterectomy Investigators: Protected Carotid-Artery Stenting versus Endarterectomy in HighRisk Patients. N Engl J Med 2004;351:14931501.

41 SPACE Collaborative Group: 30 day results from the SPACE trial of stent-protected angioplasty versus carotid endarterectomy in symptomatic patients: a randomised non-inferiority trial. Lancet 2006;368:1239-1247.

42 Eckstein HH, Ringleb P, Allenberg JR, Berger J, Fraedrich G, Hacke W, Hennerici M, Stingele R, Fiehler J, Zeumer H, Jansen O: Results of the Stent-Protected Angioplasty versus Carotid Endarterectomy (SPACE) study to treat symptomatic stenoses at 2 years: a multinational, prospective, randomised trial. Lancet Neurol 2008;7:893902.

43 Mas JL, Chatellier G, Beyssen B, Branchereau A, Moulin T, Becquemin JP, Larrue V, Lièvre M, Leys D, Bonneville JF, Watelet J, Pruvo JP, Albucher JF, Viguier A, Piquet P, Garnier P, Viader F, Touzé E, Giroud M, Hosseini H, Pillet JC, Favrole P, Neau JP, Ducrocq X, EVA-3S Investigators: Endarterectomy versus stenting in patients with symptomatic severe carotid stenosis. N Engl J Med 2006;355:1660-1671. 